Published in final edited form as:

Curr Treat Options Neurol. 2017 July ; 19(7): 26. doi:10.1007/s11940-017-0461-6.

\title{
Treatment of Sleep Dysfunction in Parkinson's Disease
}

\author{
Amy W. Amara, MD, PhD ${ }^{1,{ }^{*}}$, Lana M. Chahine, $\mathbf{M D}^{2}$, and Aleksandar Videnovic, $\mathrm{MD}^{3}$ \\ ${ }^{1}$ Division of Movement Disorders, Department of Neurology, University of Alabama at \\ Birmingham, SC 360A, 1720 2nd Ave S, Birmingham, AL, 35294-0017, USA \\ 2Parkinson's Disease and Movement Disorders Center, Department of Neurology, Perelman \\ School of Medicine, University of Pennsylvania, Philadelphia, PA, USA \\ ${ }^{3}$ Neurobiological Clinical Research Institute, Department of Neurology, Massachusetts General \\ Hospital, Harvard Medical School, Boston, MA, USA
}

\section{Opinion statement}

Impaired sleep and alertness affect the majority of Parkinson's disease (PD) patients, negatively impacting safety and quality of life. The etiology of impaired sleep-wake cycle in PD is multifactorial and encompasses medication side effects, nocturnal PD motor symptoms, and presence of co-existent sleep and neuropsychiatric disorders. The primary neurodegenerative process of $\mathrm{PD}$ involves brain regions that regulate the sleep-wake cycle, such as brainstem and hypothalamic nuclei. Sleep disorders in PD include insomnia, REM sleep behavior disorder (RBD), sleep disordered breathing (SDB), restless legs syndrome (RLS), and circadian disruption. Despite its high prevalence in the PD population, there is a paucity of clinical studies that have investigated treatment of sleep dysfunction associated with PD. Therefore, we aim to review available evidence and outline treatment strategies for improvement of disorders of sleep and wakefulness in PD patients. Evidence supporting the efficacy of pharmacological and nonpharmacological treatment strategies in PD is limited. There is thus a great need but also opportunity for development of well-designed clinical trials for impaired sleep and alertness in PD. Providing education about sleep hygiene and strategies for its implementation represents the initial step in management. Prompt diagnosis and treatment of co-existent primary sleep and psychiatric disorders are critical, as this may significantly improve sleep and alertness. While the optimal treatment for insomnia in PD has not been established, available strategies include cognitive-behavioral therapy, medications with soporific properties, and light therapy. Safety measures, clonazepam, and melatonin are the mainstay of treatment for RBD. Continuous positive airway pressure is an effective treatment for SDB in PD. The treatment algorithm for RLS associated with PD mirrors that used for idiopathic RLS. Circadian disruption has emerged as an

* amyamara@uab.edu.

Conflict of Interest

L.M.C. declares no conflict of interest.

Compliance with Ethical Standards

Human and Animal Rights and Informed Consent

All reported studies/experiments with human or animal subjects performed by the authors have been previously published and complied with all applicable ethical standards (including the Helsinki declaration and its amendments, institutional/national research committee standards, and international/national/institutional guidelines). 
important etiology of impaired sleep-wake cycles in PD, and circadian-based interventions hold promise for novel treatment approaches.

\section{Keywords}

Parkinson's disease; Sleep; Excessive daytime sleepiness; Non-motor symptoms; REM sleep behavior disorder; Circadian rhythm disorder

\section{Introduction}

Although Parkinson's disease (PD) is diagnosed by its motor symptoms of bradykinesia, rigidity, rest tremor, and postural instability, non-motor symptoms are also prevalent and are often more disabling than the motor symptoms [1,2]. Sleep dysfunction is one of the most common of these non-motor symptoms, affecting up to $98 \%$ of PD patients [3, 4]. Sleep complaints include sleep fragmentation, insomnia, parasomnias such as rapid eye movement (REM) sleep behavior disorder (RBD), excessive daytime sleepiness (EDS), circadian dysfunction, and restless legs syndrome and periodic limb movements of sleep [5]. Sleep dysfunction adversely affects quality of life (QOL), increases caregiver burden, and, in the case of EDS, can result in inability to safely complete tasks such as driving [6-8].

Sleep dysfunction in PD is multifactorial, influenced by various factors related to the disease and its treatment. The motor symptoms of PD can contribute to sleep fragmentation and insomnia. For example, bradykinesia and rigidity can lead to impaired bed mobility and nocturnal dystonia can cause nocturnal pain and discomfort [9-11]. Additionally, tremor can reemerge during microarousals and sleep stage transitions, contributing to sleep maintenance insomnia [12]. Medications used to treat PD can improve these motor symptoms, but can also contribute to nocturnal sleep problems and EDS [13].

Sleep disorders in PD are also influenced by and interact with other common non-motor symptoms. For example, autonomic dysfunction can cause nocturia, which contributes to worsened subjective and objective sleep in PD [14, 15]. Additionally, mood disorders, including depression and anxiety, are correlated with nocturnal and daytime sleep dysfunction in PD and depression predicts development of insomnia [16-19]. Sleep dysfunction, including RBD, sleep fragmentation, and daytime sleepiness, are also associated with psychosis and hallucinations in PD [5, 20]. Importantly, excessive daytime sleepiness has been demonstrated to be predictive of several neuropsychiatric disorders including depression and psychotic symptoms, and both EDS and RBD are predictive of cognitive decline [21-25]. Further, cognitive dysfunction contributes to sleep disturbances including insomnia and EDS, and is associated with RBD [26-28].

In addition to the constellation of PD-related symptoms and treatments that can contribute to sleep dysfunction, PD patients can also experience primary sleep disorders, such as restless legs syndrome (RLS), periodic limb movements of sleep (PLMS), and sleep apnea [5, 29]. These disorders contribute to worsened subjective sleep quality and objective sleep measures and can be associated with worsened depression and cognition [29-31]. Appropriate 
recognition of these primary sleep disorders is important due to their negative influence on QOL in patients with PD [30].

The recognition of the many factors that can contribute to nocturnal and daytime sleep dysfunction in PD is important for optimizing treatment of sleep complaints for individual patients. This review will discuss pharmacologic and non-pharmacologic treatment strategies for improving sleep and alertness in patients with PD. We will explore treatments that act directly on sleep symptoms such as insomnia and daytime sleepiness and also review treatment of motor and non-motor symptoms that indirectly influence sleep and vigilance in PD.

\section{Pharmacologic therapies}

\section{Dopaminergic medications}

Dopamine plays an essential role in the regulation of the sleep-wake cycle. For example, medications that increase the synaptic availability of dopamine, such as amphetamines, promote alertness. This supports the traditional view of dopamine-related wake-promoting properties. Degeneration of the dopaminergic system therefore may be one mechanism underlying the EDS that is common in PD. Dopamine, however, may also trigger hypersomnolence. While stimulation of D1 receptors results in wake-promoting effects, differential responses may be seen with stimulation of D2 and D3 receptors depending of the dose of the drug [32]. Dopamine also has important connections with the human circadian system [33]. This likely bi-directional relationship is important for sleep-wake homeostasis.

Studies reporting the effects of dopaminergic medications on sleep reveal contradictory findings. While most of these studies evaluate motor function as the primary outcome, some studies also report effects of these medications on sleep. Studies of pramipexole, transdermal rotigotine, and extended-release formulations of levodopa and ropinirole show significant improvements in sleep quality [34-37]. The CLEOPATRA-PD clinical trial, which compared the efficacy of pramipexole and rotigotine, demonstrated significant improvements in sleep as assessed by the Parkinson's Disease Sleep Scale (PDSS) [34]. Extended release ropinirole as adjunctive therapy to levodopa was studied in the EASE-PD clinical trial and revealed favorable effects on sleep quality [36]. In the RECOVER clinical trial, transdermal rotigotine improved sleep as assessed by the PDSS-2 [37]. Observed benefits of dopamine agonists appear to be modulated by improvements in overnight motor PD symptoms, but other mechanisms may be involved as well. For example, dopaminergic medications are useful in the treatment of RLS in other populations, although there are no randomized controlled trials (RCTs) evaluating RLS treatment in PD [5]. Collectively, these studies suggest that extended-release dopamine agonists may have a role in the management of sleep disturbances in PD.

Equally importantly, other studies link levodopa and dopamine agonists with worsened sleep, including the development of insomnia, which may be a dose-dependent phenomenon $[38,39]$. Levodopa and dopamine agonists have been also associated with EDS and sudden onset sleep, so-called sleep attacks. Potential risks of dopamine agonist-associated sleepiness, including sleep attacks, should be considered when prescribing dopaminergic 
therapies to improve overnight sleep. Other classes of dopaminergic therapies can also influence sleep. For example, selegiline can have stimulant properties that exacerbate insomnia [40].

\section{Non-benzodiazepine sedative hypnotic agents}

Non-benzodiazepine sedative hypnotic agents include zolpidem, zaleplon, and eszopiclone. There are limited high-level data on the safety/efficacy of hypnotic agents for treatment of sleep problems in PD. Available studies performed in the PD population have generally had very small sample sizes. In a 6-week study of 30 PD patients with sleep onset insomnia [41], participants were randomized to eszopiclone or placebo. While total sleep time (TST) (the primary outcome) did not improve, number of awakenings, quality of sleep, and the physician-rated clinical global impression scale were all significantly better in the eszopiclone arm. Adverse events were not significantly different between the treatment arms. Based on recommendations in the general older adult population, non-benzodiazepine sedative hypnotic agent use in PD should be limited to brief treatment duration while alternative treatments, including cognitive-behavioral therapy, are being administered [42].

\section{Benzodiazepines}

Benzodiazepines used for sleep include short-acting benzodiazepines such as triazolam, temazepam, flurazepam, and lorazepam as well as longer-acting benzodiazepines such as clonazepam. Given the risks associated with benzodiazepine use, including increased risk of falls and cognitive impairment, their use in older adults, including PD, should generally be avoided [42].

Unfortunately, therapies for RBD are limited, and clonazepam remains the mainstay of treatment for RBD (along with melatonin; see below) [43]. Data supporting the efficacy of clonazepam for RBD in PD is limited. Studies in the so-called idiopathic RBD population (individuals with RBD without a diagnosed neurodegenerative disorder) are also limited, with no large RCTs available. However, retrospective studies and large case series suggest that clonazepam reduces dream enactment and thus risk of injury [43].

Data supporting the use of benzodiazepines for other sleep disorders in PD are limited. In the appropriate clinical context, they may be considered for nocturnal anxiety, panic attacks, periodic limb movement disorder, and even sleep fragmentation insomnia, but only in cases where potential benefits outweigh potential risks. For example, in a PD patient with REM sleep behavior disorder, sleep onset and sleep maintenance insomnia, and PLMD, the potential benefits of clonazepam may outweigh the medication-related risks, as well as the risks of polypharmacy should each sleep problem be targeted with differing pharmacotherapy.

\section{Psychotropic medication}

In treating neuropsychiatric symptoms in PD patients with co-morbid sleep disorders, several principles of rational pharmacotherapy warrant consideration. First, when possible, psychotropic medications that can be used to treat both the neuropsychiatric symptoms as well as the co-morbid sleep disorder should be selected. Second, potential worsening of co- 
morbid sleep problems as an adverse effect of a given psychotropic should always be considered. For example, many anti-depressants can worsen RBD and RLS, as discussed further below. There are limited high-level data on the safety/efficacy of psychotropic medications for sleep problems in PD, but data from a few studies in PD and from several studies in the general older adult population provide for some guidance in this regard. See Table 1 for more information.

Anti-psychotics-The majority of anti-psychotics are recommended against in PD as they can significantly worsen Parkinsonism [49]. However, there are some exceptions namely quetiapine, clozapine, and pimavanesrin.

Quetiapine is widely used in PD [50] despite lack of evidence for its efficacy [51] and increased risk of various adverse effects including increased mortality [52, 53]. However, given limited treatment options for psychosis in PD, its use in PD may be justified in select cases. For example, in patients with significant nocturnal psychotic symptoms, it may be considered when other pharmacologic and non-pharmacologic measures have not been successful. While the use of quetiapine as a primary treatment for insomnia should be avoided [54•], its sedating properties can be leveraged in the latter situation. A small study in PD suggests a beneficial effect on nocturnal visual hallucinations without a significant effect on most sleep measures [55]. However, non-significant improvements in several objective sleep measures were noted including increased TST and reduced wake time after sleep onset [55].

Of all the anti-psychotics, clozapine has the highest level of evidence supporting its efficacy for PD psychosis. Unfortunately, risk of agranulocytosis, as well as the impracticality of the required frequent blood monitoring, limits its use. There are some data to suggest clozapine improves sleep in PD. Large retrospective studies indicate it may improve sleep fragmentation, insomnia, sundowning, vivid dreams, and nocturnal akathesia [46]. Importantly, EDS is a common adverse event, occurring in nearly half of treated patients [46]. These data suggest that while sleep disturbance in and of itself is not an appropriate indication for clozapine therapy, in patients with PD psychosis and significant nocturnal disturbances, consideration for clozapine should be given, but with the understanding that up to one half of treated patients will experience EDS.

Pimavanserin is a 5-HT2A inverse agonist with anti-psychotic efficacy in PD, as demonstrated in an RCT [47•]. In that trial, a secondary outcome included subjective sleep, as assessed with the Scales for Outcomes in Parkinson's Disease (SCOPA-SLEEP). Pimavanserin significantly improved SCOPA-SLEEP compared to placebo. Interestingly, there was no correlation between improvements in sleep and psychosis, which, combined with results from studies on effects of pimavanesrin on sleep in adults without PD [48], suggests that the sleep improvements due to pimavanserin may be independent of its antipsychotic effect. Additional studies are required to confirm this. However, this preliminary data does suggest that in the appropriate context, such as in PD patients with sleep disrupted by nocturnal psychotic symptoms (such as hallucinations or paranoia), pimavanserin may be considered. 
Anti-depressants-As mentioned above, depression and sleep disturbances are commonly comorbid in PD. There are some, though limited, data to support the beneficial effect of anti-depressants on sleep. The mechanism of efficacy is not known but could result from the sedating properties of the agent, improvement in mood/anxiety, or both. In RCTs that included subjective sleep measures as a secondary outcome, both venlafaxine [44] and nortriptyline were associated with improved subjective sleep compared to placebo [45]. Mirtazapine, an anti-depressant with sedating properties, is useful in older adults with comorbid insomnia and depression, but data on its use in PD is limited [42].

Several anti-depressants have sedating properties at doses lower than what would typically be administered for an anti-depressant effect. These include trazodone and doxepin. Data to support their use and safety in PD is limited, but one small pilot study reported a benefit in PD patients treated with doxepin [56•]. Data from the non-PD older adult population suggest efficacy for treatment of sleep maintenance insomnia with good tolerability [42]. Duloxetine is an NSRI that is efficacious for several etiologies of pain including fibromyalgia and neuropathic pain. It may be an appropriate consideration in PD patients with significant nocturnal pain, though trials supporting its use in PD have not been reported.

All selective serotonin reuptake inhibitors (SSRIs) and serotonin and norepinephrine reuptake inhibitors (SNRIs) have the risk of worsening RLS and RBD. In such instances, lowering the dose may be sufficient to mitigate the worsening, but in many cases, discontinuation and identification of another agent to treat the depression and other sleep disturbances may be required.

\section{Wake-promoting agents}

Medications used to promote wakefulness in primary disorders of hypersomnolence, such as narcolepsy, include stimulants such as dextroamphetamine, methylphenidate, modafinil, and armodafinil. Some of these medications have been tested in patients with PD. For example, methylphenidate improved subjective sleepiness as a secondary outcome in a placebocontrolled trial testing the effects of this medication on gait dysfunction in PD patients after deep brain stimulation [57]. The most common adverse effects of methylphenidate in this study were elevation of heart rate and weight loss [57]. Modafinil has been tested in three small RCTs with varying results. Two studies demonstrated improvement in subjective sleepiness with modafinil, while another showed no significant improvement compared to placebo [58-60]. Modafinil did not alter objective measures of sleepiness [58, 60]. A recent meta-analysis of these three trials demonstrated evidence for improvement in subjective EDS due to modafinil in PD [61•]. Caffeine has also been studied in a placebo-controlled manner for EDS in PD, but showed only a trend toward reduction in scores on the Epworth Sleepiness Scale. In an open-label study, orally disintegrating selegiline was shown to significantly reduce EDS, but the trial included concurrent reduction of dopamine agonist, making it difficult to determine direct impact of selegiline on sleepiness [40]. A placebocontrolled trial of atomoxetine for treatment of depression in PD did not show any improvement in depression, but did improve cognition and reduce EDS as secondary outcomes [62]. Though efficacy data is limited for these therapies, these medications are 
generally well tolerated, and it is reasonable to consider their use for EDS in PD, particularly if there is a safety risk related to the EDS.

\section{Melatonin}

Melatonin is a hormone produced by the pineal gland. Its soporific properties and synchronizing effects on the circadian system provide the basis for its therapeutic use in sleep medicine. In PD, melatonin has been primarily used for the management of insomnia and RBD. It is generally well tolerated although morning sleepiness and headaches have been reported. Despite its relatively common use in the PD population, RCTs of melatonin in PD are scarce. Long-term data on the efficacy of melatonin in treating sleep disorders in PD are not available, though short-term studies are promising.

In an RCT of 18 PD patients, treatment with melatonin $(3 \mathrm{mg})$ resulted in significant improvements in sleep quality as assessed by the Pittsburgh Sleep Quality Index (PSQI) [63, 64]. PSG-derived sleep metrics, however, did not differ between placebo and melatonin groups. Treatment with melatonin was well tolerated without impact on motor performance.

In another double-blind, placebo-controlled, cross-over clinical trial, 40 PD patients were treated with either melatonin 5 or $50 \mathrm{mg}$, or placebo [63, 64]. Nocturnal sleep was assessed by actigraphy and sleep diaries, whereas daytime sleepiness and function were assessed with questionnaires. A statistically significant improvement in total nighttime sleep time by 10 min was observed during the $50 \mathrm{mg}$ melatonin treatment compared to $5 \mathrm{mg}$ or placebo, but this is of unclear clinical significance. Significant improvement in subjective sleep disturbance, sleep quantity, and daytime sleepiness were seen during the $5 \mathrm{mg}$ melatonin treatment compared to placebo.

Supraphysiological doses of melatonin in patients with RBD reduce abnormal motor and vocal behaviors and restore muscle atonia in REM sleep [65]. The mechanism of action of melatonin in RBD remains unknown. Several case series documented beneficial effects of melatonin for RBD with daily doses up to $12 \mathrm{mg}$ [66-68]. A double-blind, placebocontrolled, cross-over trial of melatonin in 8 male patients with mild RBD revealed complete resolution of dream enactment behaviors in $4 / 8$ patients, partial resolution in $3 / 8$, and no change in 1 patient [69]. Higher doses of melatonin at bedtime (6-15 mg) restore REM atonia in association with disappearance of RBD symptoms [69]. An open-label clinical trial of the melatonin receptor agonist, ramelteon, demonstrated improvements of RBD in a cohort of 35 PD patients with co-existent sleep disturbances [70].

\section{Miscellaneous}

Suvorexant is an orexin antagonist. Studies of suvorexant for treatment of insomnia in the general older adult population are limited but suggest it can be efficacious and well tolerated in this patient population [71]. It has not been studied in PD.

Gabapentin is an anti-convulsant that has demonstrated efficacy for neuropathic pain as well as restless leg syndrome in the general population, with a fair amount of data available on its efficacy and safety in older adults [72,73]. While data on its utility in PD are limited, in PD patients with RLS and/or neuropathic pain, gabapentin may be considered. 
Agomelatine is melatonin MT1/MT2 receptor agonist and $5 \mathrm{HT}_{2 \mathrm{c}}$ receptor antagonist that improved sleep quality and daytime sleepiness and reduced nocturnal awakenings in an open-label trial in patients with PD [74]. Randomized, controlled trials in PD are not yet available for this medication.

Sodium oxybate is a medication used to treat cataplexy and EDS in narcolepsy and has been tested in PD patients in an open-label study [75]. The 27 participants who completed the study had significant improvements in subjective sleepiness, sleep quality, and fatigue as well as a significant objective improvement in slow wave sleep by polysomnography, but also showed an increase in the apnea hypopnea index [75].

Rivastigmine is a cholinesterase inhibitor that is indicated for treatment of dementia in PD and Alzheimer's disease. One small $(n=12)$, double-blind, placebo-controlled, cross-over study investigated rivastigmine in patients with PD who had RBD [76]. Rivastigmine treatment was associated with reduced frequency of RBD episodes.

\section{Non-pharmacologic therapies}

Because medication therapies have the potential for detrimental side effects, nonpharmacologic therapies offer a promising alternative for treatment of sleep disorders in PD. However, similar to studies on pharmacologic therapies for sleep-related therapy in PD, there are few RCTs investigating the efficacy of non-pharmacologic treatments. In this section, we will discuss available evidence for use of exercise, light therapy, and cognitivebehavioral therapy for disorders of sleep and wakefulness in PD.

\section{Exercise}

In healthy older adults, exercise improves both sleep quality and objective sleep outcomes, as measured by polysomnography. A meta-analysis investigating the impact of exercise on sleep showed that regular exercise in older adults improves sleep quality, reduces sleep latency, and increases TST and sleep efficiency [77]. In PD, there are limited data evaluating the impact of exercise on sleep. The only RCT demonstrated that a multimodal exercise intervention over 6 months improved subjective sleep quality and instrumental activities of daily living in patients with PD in the exercise group $(n=23)$ compared to those in the control group $(n=19)$ [78•]. There are no published studies on the effects of exercise on objective sleep outcomes in PD, nor its effects on circadian rhythm. Pilot studies suggest that group therapy exercise [79] and Qigong (a traditional Chinese meditative exercise) [80] may improve sleep in PD.

\section{Circadian-based interventions}

Circadian disruption has been demonstrated in several animal models of parkinsonism as well as in patients with early and advanced PD; this may relate to the integral role dopamine plays in regulation of circadian rhythmicity. Low circadian amplitude has been linked with EDS associated with PD. There is thus a strong rationale for the exploration of circadianbased interventions for impaired sleep and alertness in PD. 
Applications of light therapy, melatonin, and physical exercise are common circadian-based treatment interventions used for treatment of primary sleep and psychiatric disorders in the non-PD population. In PD, melatonin has mainly been primarily used in the treatment of insomnia and RBD (above). Circadian properties of melatonin have not yet been explored as a treatment strategy for improving sleep-wake cycles in PD.

Supplementary exposure to bright light (light therapy, LT) has shown beneficial effects on sleep quality and daytime vigilance in healthy elderly as well as patients with dementia [8186]. Reported effect sizes of LT are equivalent or superior to psychopharmacological treatments [87]. Activation of the SCN has been hypothesized as one of the mechanisms of bright environmental light effects on mood, sleep, and circadian rhythms [88, 89]. To date, several studies have been published on LT in PD [90-92]. In a series of 12 PD patients with insomnia and/or depressive symptoms, bright LT of 1000-1500 lx administered for 60-90 min prior to the habitual bedtime over a 2-week period resulted in improved sleep onset latency, sleep continuity, and mood [90]. In an open-label study, 120 PD patients were prescribed bright LT at the dose of 4000 to $6000 \mathrm{~lx}$ for $60 \mathrm{~min}$ prior to the habitual bedtime and were followed from a few months to 8 years [91]. Patients with good compliance achieved improvements in mood, anxiety, and tests of motor function. In another controlled LT study, 36 PD patients were randomized to receive bright LT with 7500 lx or placebo LT of $950 \mathrm{~lx}$ for $30 \mathrm{~min}$ in the morning during a 2-week period [92]. Bright LT was associated with significantly improved Unified Parkinson Disease Rating Scale (UPDRS) part I and II scores, and modest improvements in mood and daytime sleepiness.

In the most recent clinical trial of LT in $\mathrm{PD}, 31$ patients receiving stable dopaminergic therapy with co-existent EDS and without cognitive impairment or primary sleep disorder were randomized 1:1 to receive bright LT or dim-red LT (control condition) twice daily in 1$\mathrm{h}$ intervals for 14 days [93•]. Bright LT resulted in significant improvements in EDS as assessed by the ESS. Both bright LT and dim-red LT were associated with improvements in sleep quality as captured by the PSQI and the PDSS. Bright LT improved several selfreported sleep metrics, including sleep fragmentation, sleep quality, and ease of falling asleep. Light therapy was associated with increased daily physical activity as assessed by actigraphy. Of interest are also improvements in UPDRS part I, II, and III scores after the LT intervention.

In summary, these studies demonstrate beneficial effects of bright LT on sleep, mood, and non-motor function in PD. LT, already widely used in sleep medicine, holds a promise as a non-pharmacological treatment intervention for disruptions of sleep and alertness in PD.

\section{Cognitive-behavioral therapy}

Another non-pharmacologic intervention that has been used successfully to treat insomnia in non-PD populations is cognitive-behavioral therapy for insomnia (CBT-I). The American Academy of Sleep Medicine recommends this intervention as treatment for insomnia [94]. CBT-I teaches patients to change dysfunctional behaviors and thinking patterns that contribute to their sleep impairment and employs methods such as stimulus control, cognitive therapy for dysfunctional thinking, sleep relaxation, sleep hygiene instruction, and sleep restriction [94]. In healthy adults with insomnia, a meta-analysis demonstrated that 
CBT-I reduces sleep latency and wake after sleep onset and increases sleep efficiency [95]. Additionally, in patients with insomnia and another comorbid condition, including psychiatric disease, COPD, kidney disease, cancer, chronic pain, and osteoarthritis, another meta-analysis showed that CBT-I is effective for insomnia in the setting of other psychiatric and medical diagnoses [96]. We are aware of only one small study that evaluated CBT-I in PD. This randomized, controlled study evaluated three groups of six patients: CBT-I in combination with light therapy, doxepin, and control. The CBT-I/light therapy group showed improvement in the Insomnia Severity Index, PDSS, and examiner-reported clinical global impression of change, but showed a worsening of quality of life [56•]. The success of CBT-I in other populations suggests that further study is warranted to evaluate its effects on PD patients with insomnia.

\section{Summary}

Impaired sleep and alertness are common in the PD population. Its causes are multifactorial, which adds to the complexity of the treatment. Despite the wide range of sleep disturbance in PD and its major clinical impact, almost no systematic treatment studies have been performed. This emphasizes the need to focus efforts on development and execution of clinical trials that will lead to optimization of existing treatments as well as development of novel treatment modalities for various aspects of sleep, wakefulness, and circadian disturbances in PD.

\section{Acknowledgements}

The authors receive funding from NIH NINDS (K23NS080912, A.W.A.; P50NS053488, L.M.C.; R01NS099055, A.V.; K23NS07228, A.V.).

A.W.A. is a site investigator for clinical trials sponsored by AbbVie and another by Axovant. No information related to these trials was included in this publication.

A.V. reports a grant from NIH/NINDS.

\section{References and Recommended Reading}

Papers of particular interest, published recently, have been highlighted as:

- Of importance

1. Barone P, Antonini A, Colosimo C, Marconi R, Morgante L, Avarello TP, et al. The PRIAMO study: a multicenter assessment of nonmotor symptoms and their impact on quality of life in Parkinson's disease. Mov Disord. 2009;24(11):1641-9. [PubMed: 19514014]

2. Martinez-Martin P, Schapira AH, Stocchi F, Sethi K, Odin P, MacPhee G, et al. Prevalence of nonmotor symptoms in Parkinson's disease in an international setting; study using nonmotor symptoms questionnaire in 545 patients. Mov Disord. 2007;22(11):1623-9. [PubMed: 17546669]

3. Lees AJ, Blackburn NA, Campbell VL. The nighttime problems of Parkinson's disease. Clin Neuropharmacol. 1988;11(6):512-9. [PubMed: 3233589]

4. Simuni T, Sethi K. Nonmotor manifestations of Parkinson's disease. Ann Neurol. 2008;64(Suppl 2):S65-80. [PubMed: 19127582]

5. Chahine LM, Amara AW, Videnovic A. A systematic review of the literature on disorders of sleep and wakefulness in Parkinson's disease from 2005 to 2015. Sleep Med Rev. 2016. doi:10.1016/ j.smrv.2016.08.001 
6. Gomez-Esteban JC, Tijero B, Somme J, Ciordia R, Berganzo K, Rouco I, et al. Impact of psychiatric symptoms and sleep disorders on the quality of life of patients with Parkinson's disease. J Neurol. 2011;258(3):494-9. [PubMed: 20957384]

7. Ozdilek B, Gunal DI. Motor and non-motor symptoms in Turkish patients with Parkinson's disease affecting family caregiver burden and quality of life. J Neuropsychiatry Clin Neurosci. 2012;24(4): 478-83. [PubMed: 23224455]

8. Uc EY, Rizzo M, Anderson SW, Sparks JD, Rodnitzky RL, Dawson JD. Driving with distraction in Parkinson disease. Neurology. 2006;67(10):1774-80. [PubMed: 17130409]

9. Gomez-Esteban JC, Zarranz JJ, Lezcano E, Velasco F, Ciordia R, Rouco I, et al. Sleep complaints and their relation with drug treatment in patients suffering from Parkinson's disease. Mov Disord: Off J Mov Disord Soc. 2006;21(7):983-8.

10. Dhawan V, Dhoat S, Williams AJ, Dimarco A, Pal S, Forbes A, et al. The range and nature of sleep dysfunction in untreated Parkinson's disease (PD). A comparative controlled clinical study using the Parkinson's disease sleep scale and selective polysomnography. J Neurol Sci. 2006;248(1-2): 158-62. [PubMed: 16780888]

11. Louter M, van Sloun RJ, Pevernagie DA, Arends JB, Cluitmans PJ, Bloem BR, et al. Subjectively impaired bed mobility in Parkinson disease affects sleep efficiency. Sleep Med. 2013;14(7):66874. [PubMed: 23643658]

12. Garcia-Borreguero D, Larrosa O, Bravo M. Parkinson's disease and sleep. Sleep Med Rev. 2003;7(2):115-29. [PubMed: 12628213]

13. Verbaan D, van Rooden SM, Visser M, Marinus J, van Hilten JJ. Nighttime sleep problems and daytime sleepiness in Parkinson's disease. Mov Disord: Off J Mov Disord Soc. 2008;23(1):35-41.

14. Vaughan CP, Juncos JL, Trotti LM, Johnson TM, 2nd, Bliwise DL. Nocturia and overnight polysomnography in Parkinson disease. Neurourol Urodyn. 2013;32(8):1080-5. [PubMed: 23359220]

15. Bhidayasiri R, Mekawichai P, Jitkritsadakul O, Panyakaew P, Kaewwilai L, Boonrod N, et al. Nocturnal journey of body and mind in Parkinson's disease: the manifestations, risk factors and their relationship to daytime symptoms. Evidence from the NIGHT-PD study. J Neural Transm (Vienna). 2014;121(Suppl 1):S59-68. [PubMed: 24682359]

16. Birchall EL, Walker HC, Cutter G, Guthrie S, Joop A, Memon RA, et al. The effect of unilateral subthalamic nucleus deep brain stimulation on depression in Parkinson's disease. Brain Stimul. 2016;10(3):651-656 doi:10.1016/j.brs.2016.12.014 [PubMed: 28065487]

17. Suzuki K, Miyamoto M, Miyamoto T, Okuma Y, Hattori N, Kamei S, et al. Correlation between depressive symptoms and nocturnal disturbances in Japanese patients with Parkinson's disease. Parkinsonism Relat Disord. 2009;15(1):15-9. [PubMed: 18359262]

18. Kurtis MM, Rodriguez-Blazquez C, Martinez-Martin P. Relationship between sleep disorders and other non-motor symptoms in Parkinson's disease. Parkinsonism Relat Disord. 2013;19(12):11525. [PubMed: 23953775]

19. Wegelin J, McNamara P, Durso R, Brown A, McLaren D. Correlates of excessive daytime sleepiness in Parkinson's disease. Parkinsonism Relat Disord. 2005;11(7):441-8. [PubMed: 16154796]

20. Lee AH, Weintraub D. Psychosis in Parkinson's disease without dementia: common and comorbid with other non-motor symptoms. Mov Disord: Off J Mov Disord Soc. 2012;27(7):858-63.

21. Anang JB, Gagnon JF, Bertrand JA, Romenets SR, Latreille V, Panisset M, et al. Predictors of dementia in Parkinson disease: a prospective cohort study. Neurology. 2014;83(14):1253-60. [PubMed: 25171928]

22. Ataide M, Franco CM, Lins OG. Daytime sleepiness and Parkinson's disease: the contribution of the multiple sleep latency test. Sleep Disord. 2014;2014:767181. [PubMed: 25126427]

23. Chahine LM, Xie SX, Simuni T, Tran B, Postuma R, Amara A, et al. Longitudinal changes in cognition in early Parkinson's disease patients with REM sleep behavior disorder. Parkinsonism Relat Disord. 2016;27:102-6. [PubMed: 27010070]

24. Naismith SL, Hickie IB, Lewis SJ. The role of mild depression in sleep disturbance and quality of life in Parkinson's disease. J Neuropsychiatry Clin Neurosci. 2010;22(4):384-9. [PubMed: 21037122] 
25. Zhu K, van Hilten JJ, Putter H, Marinus J. Risk factors for hallucinations in Parkinson's disease: results from a large prospective cohort study. Mov Disord: Off J Mov Disord Soc. 2013;28(6):75562.

26. Postuma RB, Bertrand JA, Montplaisir J, Desjardins C, Vendette M, Rios Romenets S, et al. Rapid eye movement sleep behavior disorder and risk of dementia in Parkinson's disease: a prospective study. Mov Disord: Off J Mov Disord Soc. 2012;27(6):720-6.

27. Erro R, Santangelo G, Picillo M, Vitale C, Amboni M, Longo K, et al. Link between non-motor symptoms and cognitive dysfunctions in de novo, drug-naive PD patients. J Neurol. 2012;259(9): 1808-13. [PubMed: 22310940]

28. Gjerstad MD, Alves G, Wentzel-Larsen T, Aarsland D, Larsen JP. Excessive daytime sleepiness in Parkinson disease: is it the drugs or the disease? Neurology. 2006;67(5):853-8. [PubMed: 16966550]

29. Verbaan D, van Rooden SM, van Hilten JJ, Rijsman RM. Prevalence and clinical profile of restless legs syndrome in Parkinson's disease. Mov Disord: Off J Mov Disord Soc. 2010;25(13):2142-7.

30. Covassin N, Neikrug AB, Liu L, Corey-Bloom J, Loredo JS, Palmer BW, et al. Clinical correlates of periodic limb movements in sleep in Parkinson's disease. J Neurol Sci. 2012;316(1-2):131-6. [PubMed: 22277375]

31. Neikrug AB, Maglione JE, Liu L, Natarajan L, Avanzino JA, Corey-Bloom J, et al. Effects of sleep disorders on the non-motor symptoms of Parkinson disease. J Clin Sleep Med : JCSM : Off Publ Am Acad Sleep Med. 2013;9(11):1119-29.

32. Monti JM, Jantos H. The roles of dopamine and serotonin, and of their receptors, in regulating sleep and waking. Prog Brain Res. 2008;172:625-46. [PubMed: 18772053]

33. Videnovic A, Lazar AS, Barker RA, Overeem S. 'The clocks that time us'—circadian rhythms in neurodegenerative disorders. Nat Rev Neurol. 2014;10(12):683-93. [PubMed: 25385339]

34. Poewe WH, Rascol O, Quinn N, Tolosa E, Oertel WH, Martignoni E, et al. Efficacy of pramipexole and transdermal rotigotine in advanced Parkinson's disease: a double-blind, doubledummy, randomised controlled trial. Lancet Neurol. 2007;6(6):513-20. [PubMed: 17509486]

35. Giladi N, Fichtner A, Poewe W, Boroojerdi B. Rotigotine transdermal system for control of early morning motor impairment and sleep disturbances in patients with Parkinson's disease. J Neural Transm (Vienna). 2010;117(12):1395-9. [PubMed: 21080009]

36. Pahwa R, Stacy MA, Factor SA, Lyons KE, Stocchi F, Hersh BP, et al. Ropinirole 24-hour prolonged release: randomized, controlled study in advanced Parkinson disease. Neurology. 2007;68(14):1108-15. [PubMed: 17404192]

37. Trenkwalder C, Kies B, Rudzinska M, Fine J, Nikl J, Honczarenko K, et al. Rotigotine effects on early morning motor function and sleep in Parkinson's disease: a double-blind, randomized, placebo-controlled study (RECOVER). Mov Disord. 2011;26(1):90-9. [PubMed: 21322021]

38. Block G, Liss C, Reines S, Irr J, Nibbelink D. Comparison of immediate-release and controlled release carbidopa/levodopa in Parkinson's disease. A multicenter 5-year study. The CR first study group. Eur Neurol. 1997;37(1):23-7. [PubMed: 9018028]

39. Watts RL, Lyons KE, Pahwa R, Sethi K, Stern M, Hauser RA, et al. Onset of dyskinesia with adjunct ropinirole prolonged-release or additional levodopa in early Parkinson's disease. Mov Disord. 2010;25(7):858-66. [PubMed: 20461803]

40. Lyons KE, Friedman JH, Hermanowicz N, Isaacson SH, Hauser RA, Hersh BP, et al. Orally disintegrating selegiline in Parkinson patients with dopamine agonist-related adverse effects. Clin Neuropharmacol. 2010;33(1):5-10. [PubMed: 19855267]

41. Menza M, Dobkin RD, Marin H, Gara M, Bienfait K, Dicke A, et al. Treatment of insomnia in Parkinson's disease: a controlled trial of eszopiclone and placebo. Mov Disord: Off J Mov Disord Soc. 2010;25(11):1708-14.

42. Schutte-Rodin S, Broch L, Buysse D, Dorsey C, Sateia M. Clinical guideline for the evaluation and management of chronic insomnia in adults. J Clin Sleep Med: JCSM : Off Publ Am Acad Sleep Med. 2008;4(5):487-504.

43. Aurora RN, Zak RS, Maganti RK, Auerbach SH, Casey KR, Chowdhuri S, et al. Best practice guide for the treatment of REM sleep behavior disorder (RBD). J Clin Sleep Med: JCSM : Off Publ Am Acad Sleep Med. 2010;6(1):85-95. 
44. Richard IH, McDermott MP, Kurlan R, Lyness JM, Como PG, Pearson N, et al. A randomized, double-blind, placebo-controlled trial of antidepressants in Parkinson disease. Neurology. 2012;78(16):1229-36. [PubMed: 22496199]

45. Menza M, Dobkin RD, Marin H, Mark MH, Gara M, Buyske S, et al. A controlled trial of antidepressants in patients with Parkinson disease and depression. Neurology. 2009;72(10):88692. [PubMed: 19092112]

46. Trosch RM, Friedman JH, Lannon MC, Pahwa R, Smith D, Seeberger LC, et al. Clozapine use in Parkinson's disease: a retrospective analysis of a large multicentered clinical experience. Mov Disord: Off J Mov Disord Soc. 1998;13(3):377-82.

47. Cummings J, Isaacson S, Mills R, Williams H, Chi-Burris K, Corbett A, et al. Pimavanserin for patients with Parkinson's disease psychosis: a randomised, placebo-controlled phase 3 trial. Lancet. 2014;383(9916):533-40. [PubMed: 24183563] This RCT of pimavanserin, a serotonin inverse agonist, for psychosis in PD suggested a possible benefit on sleep as well (a secondary outcome).

48. Ancoli-Israel S, Vanover KE, Weiner DM, Davis RE, van Kammen DP. Pimavanserin tartrate, a 5$\mathrm{HT}(2 \mathrm{~A})$ receptor inverse agonist, increases slow wave sleep as measured by polysomnography in healthy adult volunteers. Sleep Med. 2011;12(2):134-41. [PubMed: 21256805]

49. Seppi K, Weintraub D, Coelho M, Perez-Lloret S, Fox SH, Katzenschlager R, et al. The Movement Disorder Society evidence-based medicine review update: treatments for the non-motor symptoms of Parkinson's disease. Mov Disord: Off J Mov Disord Soc. 2011;26(Suppl 3):S42-80.

50. Weintraub D, Chen P, Ignacio RV, Mamikonyan E, Kales HC. Patterns and trends in antipsychotic prescribing for Parkinson disease psychosis. Arch Neurol. 2011;68(7):899-904. [PubMed: 21747029]

51. Desmarais P, Massoud F, Filion J, Nguyen QD, Bajsarowicz P. Quetiapine for psychosis in Parkinson disease and neurodegenerative parkinsonian disorders: a systematic review. J Geriatr Psychiatry Neurol. 2016;29(4):227-36. [PubMed: 27056066]

52. Weintraub D, Chiang C, Kim HM, Wilkinson J, Marras C, Stanislawski B, et al. Association of antipsychotic use with mortality risk in patients with Parkinson disease. JAMA Neurology. 2016;73(5):535-41. [PubMed: 26999262]

53. Weintraub D, Chiang C, Kim HM, Wilkinson J, Marras C, Stanislawski B, et al. Antipsychotic use and physical morbidity in Parkinson disease. Am J Geriatr Psychiatry. 2017. doi:10.1016/j.jagp. 2017.01.076

54•. Thompson W, Quay TA, Rojas-Fernandez C, Farrell B, Bjerre LM. Atypical antipsychotics for insomnia: a systematic review. Sleep Med. 2016;22:13-7. [PubMed: 27544830] This systematic review concluded that atypical antipsychotics should be avoided in the first-line treatment ofprimary insomnia until further evidence is available.

55. Fernandez HH, Okun MS, Rodriguez RL, Malaty IA, Romrell J, Sun A, et al. Quetiapine improves visual hallucinations in Parkinson disease but not through normalization of sleep architecture: results from a double-blind clinical-polysomnography study. Int J Neurosci. 2009;119(12):2196205. [PubMed: 19916848]

56• Rios Romenets S, Creti L, Fichten C, Bailes S, Libman E, Pelletier A, et al. Doxepin and cognitive behavioural therapy for insomnia in patients with Parkinson's disease- a randomized study. Parkinsonism Relat Disord. 2013;19(7):670-5. [PubMed: 23561946] This trial is the only RCT to evaluate effects of cognitive behavioral therapy for insomnia in PD.

57. Moreau C, Delval A, Defebvre L, Dujardin K, Duhamel A, Petyt G, et al. Methylphenidate for gait hypokinesia and freezing in patients with Parkinson's disease undergoing subthalamic stimulation: a multicentre, parallel, randomised, placebo-controlled trial. Lancet Neurol. 2012;11(7):589-96. [PubMed: 22658702]

58. Hogl B, Saletu M, Brandauer E, Glatzl S, Frauscher B, Seppi K, et al. Modafinil for the treatment of daytime sleepiness in Parkinson's disease: a double-blind, randomized, crossover, placebocontrolled polygraphic trial. Sleep. 2002;25(8):905-9. [PubMed: 12489899]

59. Adler CH, Caviness JN, Hentz JG, Lind M, Tiede J. Randomized trial of modafinil for treating subjective daytime sleepiness in patients with Parkinson's disease. Mov Disord: Off J Mov Disord Soc. 2003;18(3):287-93. 
60. Ondo WG, Fayle R, Atassi F, Jankovic J. Modafinil for daytime somnolence in Parkinson's disease: double blind, placebo controlled parallel trial. J Neurol Neurosurg Psychiatry. 2005;76(12):1636-9. [PubMed: 16291885]

61•. Rodrigues TM, Castro Caldas A, Ferreira JJ. Pharmacological interventions for daytime sleepiness and sleep disorders in Parkinson's disease: systematic review and meta-analysis. Parkinsonism Relat Disord. 2016;27:25-34. [PubMed: 27010071] This meta-analysis evaluates the influence of pharmacologic interventions on nocturnal and daytime sleep dysfunction in PD.

62. Weintraub D, Mavandadi S, Mamikonyan E, Siderowf AD, Duda JE, Hurtig HI, et al. Atomoxetine for depression and other neuropsychiatric symptoms in Parkinson disease. Neurology. 2010;75(5): 448-55. [PubMed: 20679638]

63. Medeiros CA, Carvalhedo de Bruin PF, Lopes LA, Magalhaes MC, de Lourdes Seabra M, de Bruin VM. Effect of exogenous melatonin on sleep and motor dysfunction in Parkinson's disease. A randomized, double blind, placebo-controlled study. J Neurol. 2007;254(4):459-64. [PubMed: 17404779]

64. Dowling GA, Burr RL, Van Someren EJ, Hubbard EM, Luxenberg JS, Mastick J, et al. Melatonin and bright-light treatment for rest-activity disruption in institutionalized patients with Alzheimer's disease. J Am Geriatr Soc. 2008;56(2):239-46. [PubMed: 18070004]

65. McGrane IR, Leung JG, St Louis EK, Boeve BF. Melatonin therapy for REM sleep behavior disorder: a critical review of evidence. Sleep Med. 2015;16(1):19-26. [PubMed: 25454845]

66. Boeve BF, Silber MH, Ferman TJ. Melatonin for treatment of REM sleep behavior disorder in neurologic disorders: results in 14 patients. Sleep Med. 2003;4(4):281-4. [PubMed: 14592300]

67. Kunz D, Bes F. Melatonin as a therapy in REM sleep behavior disorder patients: an open-labeled pilot study on the possible influence of melatonin on REM-sleep regulation. Mov Disord. 1999;14(3):507-11. [PubMed: 10348479]

68. Takeuchi N, Uchimura N, Hashizume Y, Mukai M, Etoh Y, Yamamoto K, et al. Melatonin therapy for REM sleep behavior disorder. Psychiatry Clin Neurosci. 2001;55(3):267-9. [PubMed: 11422870]

69. Kunz D, Mahlberg R. A two-part, double-blind, placebo-controlled trial of exogenous melatonin in REM sleep behaviour disorder. J Sleep Res. 2010;19(4):591-6. [PubMed: 20561180]

70. Kashihara K, Nomura T, Maeda T, Tsuboi Y, Mishima T, Takigawa H, et al. Beneficial effects of ramelteon on rapid eye movement sleep behavior disorder associated with Parkinson's diseaseresults of a multicenter open trial. Intern Med (Tokyo, Japan). 2016;55(3):231-6.

71. Schroeck JL, Ford J, Conway EL, Kurtzhalts KE, Gee ME, Vollmer KA, et al. Review of safety and efficacy of sleep medicines in older adults. Clin Ther. 2016;38(11):2340-72. [PubMed: 27751669]

72. Garcia-Borreguero D, Silber MH, Winkelman JW, Hogl B, Bainbridge J, Buchfuhrer M, et al. Guidelines for the first-line treatment of restless legs syndrome/Willis-Ekbom disease, prevention and treatment of dopaminergic augmentation: a combined task force of the IRLSSG, EURLSSG, and the RLS-foundation. Sleep Med. 2016;21:1-11. [PubMed: 27448465]

73. Haslam C, Nurmikko T. Pharmacological treatment of neuropathic pain in older persons. Clin Interv Aging. 2008;3(1):111-20. [PubMed: 18488882]

74. Avila A, Cardona X, Martin-Baranera M, Leon L, Caballol N, Millet P, et al. Agomelatine for depression in Parkinson disease: additional effect on sleep and motor dysfunction. J Clin Psychopharmacol. 2015;35(6):719-23. [PubMed: 26444951]

75. Ondo WG, Perkins T, Swick T, Hull KL, Jr, Jimenez JE, Garris TS, et al. Sodium oxybate for excessive daytime sleepiness in Parkinson disease: an open-label polysomnographic study. Arch Neurol. 2008;65(10):1337-40. [PubMed: 18852348]

76. Di Giacopo R, Fasano A, Quaranta D, Della Marca G, Bove F, Bentivoglio AR Rivastigmine as alternative treatment for refractory REM behavior disorder in Parkinson's disease. Mov Disord: OffJ Mov Disord Soc. 2012;27(4):559-61.

77. Kredlow MA, Capozzoli MC, Hearon BA, Calkins AW, Otto MW. The effects of physical activity on sleep: a meta-analytic review. J Behav Med. 2015;38(3):427-49. [PubMed: 25596964]

78•. Nascimento CM, Ayan C, Cancela JM, Gobbi LT, Gobbi S, Stella F. Effect of a multimodal exercise program on sleep disturbances and instrumental activities of daily living performance on 
Parkinson's and Alzheimer's disease patients. Geriatr Gerontol Intern. 2014;14(2):259-66This is the only reported RCT showing impact of an exercise intervention on sleep in patients with PD.

79. Rodrigues de Paula F, Teixeira-Salmela LF, Coelho de Morais Faria CD, Rocha de Brito P, Cardoso F Impact of an exercise program on physical, emotional, and social aspects of quality of life of individuals with Parkinson's disease. Mov Disord. 2006;21(8):1073-7. [PubMed: 16637049]

80. Wassom DJ, Lyons KE, Pahwa R, Liu W. Qigong exercise may improve sleep quality and gait performance in Parkinson's disease: a pilot study. Int J Neurosci. 2015;125(8):578-84. [PubMed: 25233147]

81. Ancoli-Israel S, Martin JL, Gehrman P, Shochat T, Corey-Bloom J, Marler M, et al. Effect of light on agitation in institutionalized patients with severe Alzheimer disease. Am J Geriatr Psychiatry. 2003;11(2):194-203. [PubMed: 12611749]

82. Dowling GA, Mastick J, Hubbard EM, Luxenberg JS, Burr RL. Effect of timed bright light treatment for rest-activity disruption in institutionalized patients with Alzheimer's disease. Int J Geriatr Psychiatr. 2005;20(8):738-43.

83. Iskra-Golec I, Fafrowicz M, Marek T, Costa G, Folkard S, Foret J, et al. The effect of a change in sleep-wakefulness timing, bright light and physical exercise interventions on 24-hour patterns of performance, mood and body temperature. J Hum Ergol (Tokyo). 2001;30(1-2):261-6. [PubMed: 14564893]

84. Fetveit A, Skjerve A, Bjorvatn B. Bright light treatment improves sleep in institutionalised elderly —an open trial. Int J Geriatr Psychiatr. 2003;18(6):520-6.

85. Kobayashi R, Kohsaka M, Fukuda N, Sakakibara S, Honma H, Koyama T. Effects of morning bright light on sleep in healthy elderly women. Psychiatry Clin Neurosci. 1999;53(2):237-8. [PubMed: 10459698]

86. Kohsaka M, Fukuda N, Kobayashi R, Honma H, Sakakibara S, Koyama E, et al. Effects of short duration morning bright light in healthy elderly. II: sleep and motor activity. Psychiatry Clin Neurosci. 1998;52(2):252-3. [PubMed: 9628180]

87. Brown RE, Basheer R, McKenna JT, Strecker RE, McCarley RW. Control of sleep and wakefulness. Physiol Rev. 2012;92(3):1087-187. [PubMed: 22811426]

88. McEnany GW, Lee KA. Effects of light therapy on sleep, mood, and temperature in women with nonseasonal major depression. Issues Ment Health Nurs. 2005;26(7):781-94. [PubMed: 16126652]

89. Riemersma-van der Lek RF, Swaab DF, Twisk J, Hol EM, Hoogendijk WJ, Van Someren EJ. Effect of bright light and melatonin on cognitive and noncognitive function in elderly residents of group care facilities: a randomized controlled trial. JAMA. 2008;299(22):2642-55. [PubMed: 18544724]

90. Willis GL, Turner EJ. Primary and secondary features of Parkinson's disease improve with strategic exposure to bright light: a case series study. Chronobiol Int. 2007;24(3):521-37. [PubMed: 17612949]

91. Roehrs T, Roth T. Multiple sleep latency test: technical aspects and normal values. J Clin Neurophysiol. 1992;9(1):63-7. [PubMed: 1552009]

92. Paus S, Schmitz-Hubsch T, Wullner U, Vogel A, Klockgether T, Abele M. Bright light therapy in Parkinson's disease: a pilot study. Mov Disord: Off J Mov Disord Soc. 2007;22(10):1495-8.

93. Videnovic A, Klerman EB, Wang W, Marconi A, Kuhta T, Zee PC. Timed light therapy for sleep and daytime sleepiness associated with Parkinson disease: a randomized clinical trial. JAMA Neurol. 2017;74(4):411-418 doi: 10.1001/jamaneurol.2016.5192 [PubMed: 28241159] This recent RCT reports beneficial effects of light therapy on sleep and alertness in a cohort of PD patients with EDS.

94. Morgenthaler T, Kramer M, Alessi C, Friedman L, Boehlecke B, Brown T, et al. Practice parameters for the psychological and behavioral treatment of insomnia: an update. An American Academy of Sleep Medicine report. Sleep. 2006;29(11):1415-9. [PubMed: 17162987]

95. Trauer JM, Qian MY, Doyle JS, Rajaratnam SM, Cunnington D. Cognitive behavioral therapy for chronic insomnia: a systematic review and meta-analysis. Ann Intern Med. 2015;163(3):191-204. [PubMed: 26054060] 
96. Wu JQ, Appleman ER, Salazar RD, Ong JC. Cognitive behavioral therapy for insomnia comorbid with psychiatric and medical conditions: a meta-analysis. JAMA Intern Med. 2015;175(9):146172. [PubMed: 26147487] 


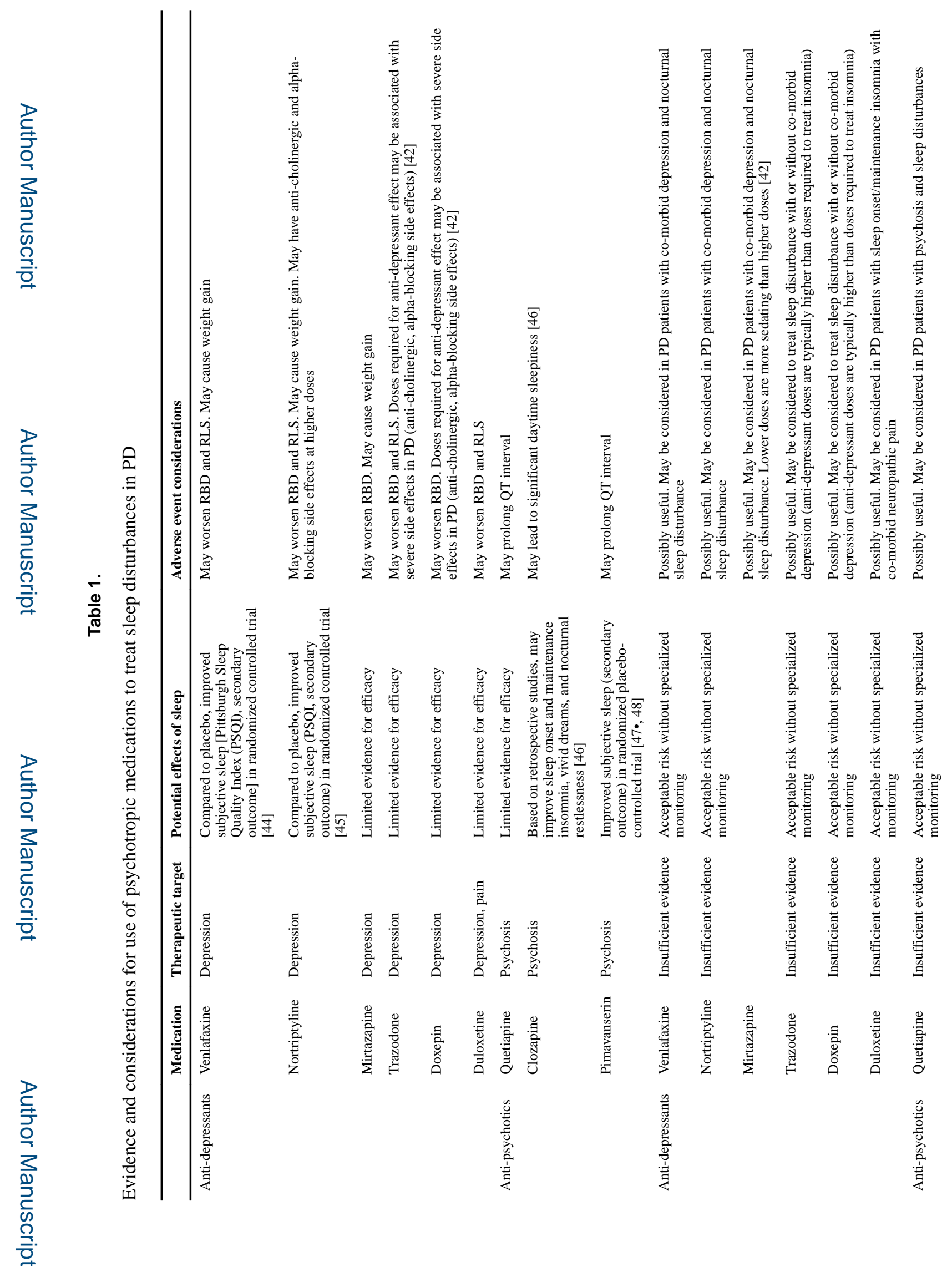

Curr Treat Options Neurol. Author manuscript; available in PMC 2019 February 12. 


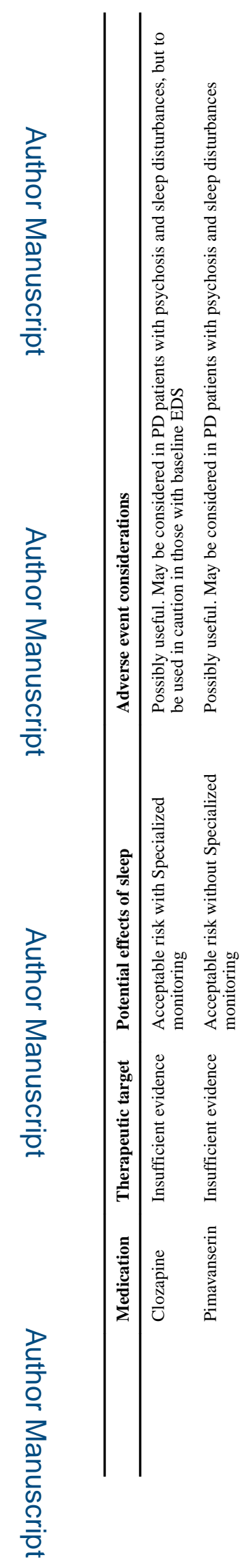

